\title{
A importância da leitura e da imaginação na infância: uma leitura de La Rogativa, de Augusto Roa Bastos
}

The importance of reading and imagination on childhood: an interpretation of La Rogativa, by Augusto Roa Bastos

\author{
Fabiane Verardi Burlamaque
}

Alexandra Verardi Burlamaque

Pedro Afonso Barth

Universidade de Passo Fundo - UPF - Passo Fundo - Rio Grande do Sul - Brasil

\begin{abstract}
Resumo: O presente artigo tem como norteamento central conduzir a uma possível leitura do conto La rogativa, do autor paraguaio Augusto Roa Bastos, tendo o objetivo de refletir sobre infância, literatura e oralidade. A presente pesquisa justifica-se devido à pertinência de dar maior visibilidade à Literatura Paraguaia. Este trabalho compreende uma interface entre a psicanálise winnicottiana e os estudos literários, especialmente ancorados nos estudos de Michèle Petit (2008). A narrativa do conto trata da trajetória de uma menina chamada Poilú, vítima da fome, da seca e da degradação, uma criança que não tinha o direito de vivenciar sua infância até encontrar um adulto que a apresentou a um mundo de lendas e magia. Concluímos que o conto não somente denuncia a realidade da seca, do abandono da população à sua própria sorte, mas também, o dano irreversível que a falta de fantasia, leitura e imaginação causam aos indivíduos.
\end{abstract}

Palavras-chave: Literatura Hispano Americana. Literatura. Infância.

Abstract: The present article has as central guid to conduct a possible reading of the tale La rogativa, from paraguayan author Augusto Roa Bastos, with the goal to reflect on childhood, literature and orality. The current research is justified to give greater visibility to Paraguayan Literature. This work comprises na interface between Winnicott's psychoanalysis theory and literature studies, especially anchored in Michèle Petit (2008) studies. The narrative of the story is about the trajectory of a girl named Poilú, hunger, drought and degradation victim, a child who didn't have the right to experience her childhood until she found and adult who introduced her to a world of legends and magic. We conclude that the story not only denounces the reality of the drought, the abandonment of the population to its own luck, but also, the irreversible damage that the lack of fantasy, reading and imagination can generate on people.

Keywords: Literature Spanish American. Literature. Childhood. 


\section{Introdução}

Augusto Roa Bastos é uma dos grandes escritores hispano americanos surgidos no século XX. Porém, ao contrário de seus pares como Gabriel García Márquez e Carlos Fuentes, o autor paraguaio - bem como a literatura paraguaia como um todo - é relativamente pouco conhecido e difundido entre nós. O que é algo que deve ser lamentado, pois a obra de Roa Bastos, além de retratar o Paraguai, é suscetível a muitas leituras e abordagens. Este trabalho propõe uma possível leitura do conto La rogativa, que trata da trajetória de uma menina chamada Poilú, vítima da fome, da seca e da degradação, uma criança que não tinha o direito de vivenciar sua infância até encontrar um adulto que a apresentou a um mundo de lendas e magia.

Tendo em vista que é pela linguagem que constituímos a literatura e a cultura, neste trabalho conduzimos uma possível leitura do conto, dialogando com a obra de Michèle Petit (2008) e a psicanálise winnicottiana. Há o consenso de que a literatura propicia uma (re)ordenação dos mecanismos de percepção do mundo, ampliando os horizontes do leitor. É o que observamos no conto com a personagem Poilú. Porém, a menina é impedida pelas forças que a cercam de se libertar e ter autonomia, uma vez que a seca, a fome e a barbárie impedem a menina de sonhar.

A presente pesquisa justifica-se pela pertinência de Roa Bastos no cenário literário e, também, para dar maior visibilidade à literatura paraguaia. Além disso, o conto permite um profícuo diálogo entre a psicanálise e os estudos literários, levando em conta que o objetivo que norteia a pesquisa é o de refletir sobre infância, literatura e oralidade a partir da leitura do conto La rogativa. O artigo será dividido em duas seções. Na primeira, contextualizamos a importância da obra de Roa Bastos para a literatura Hispano- Americana e traremos uma breve síntese do conto. Na outra parte, analisaremos o enredo do conto fazendo um cotejo interdisciplinar entre os estudos de Winnicott e Pètit.

\section{0 grito de socorro em La Rogativa}

Apesar de se localizar no centro do continente sul-americano, o Paraguai, durante muito tempo, foi um país isolado, quase como uma "ilha cercada de terra por todos os lados" (SAGUIER, 1976, p. 335). Tal isolamento foi iniciado já no período colonial, pois sendo uma terra sem metais preciosos, o Vice-reino do Peru considerava o Paraguai uma zona pobre que não merecia investimento. As sucessivas ditaduras e confrontos com países vizinhos ampliaram o isolamento e o país demorou décadas até integrar-se com seus vizinhos. Assim, o Paraguai sempre foi visto como uma terra pouco conhecida, apesar de ser um país vizinho ao Brasil. A obra de Augusto Roas Bastos pode ser apontada como um dos fatores que fizeram com que o isolamento do Paraguai diminuísse ao longo dos anos.

Nascido em 1917, em Assunção, Roa Bastos lutou na Guerra do Chaco com apenas 14 anos e sempre defendeu a liberdade de expressão. Posicionamento esse que fez com que vivesse mais da metade de sua vida exilado de sua terra natal. Porém, Roa Bastos, mesmo exilado e expulso de seu país, tornou-se a principal voz paraguaia no mundo, denunciando com contundência a violência do seu país por meio de sua obra. $O$ autor, de forma despretensiosa, deu luz e visibilidade à arte produzida no Paraguai e para os paraguaios.

Resgatar e estudar a obra de Roa Bastos, falecido em 2005, não é importante apenas para compreender o Paraguai. O estudioso de literatura paraguaia Rubén Saguier (1976, p. 336) afirma que analisar a obra de Roa Bastos e sua importância para o país auxilia na compreensão da "trajetória de uma literatura profundamente marcada pelo dramático signo da história”. Krysinski (2005, p.311) aponta que o autor paraguaio foi capaz de "traduzir através da literatura a crueldade da história e da condição humana em uma forma que revolucionou o romance histórico e que colocou sua obra no topo da arte da narração". Com Roa Bastos emergem textos profundos que não evocam apenas o "eu" paraguaio 
e forjam uma identidade para o país, mas que também analisam o comportamento humano frente a tragédias e degradações causadas pela violência.

El trueno entre las hojas (1953) foi o primeiro livro publicado de Augusto Roa Bastos a ganhar destaque nacional e internacional. A obra foi escrita enquanto Roa Bastos estava no exílio, na Argentina. Saguier (1976) aponta que uma das maiores dificuldades de consolidação da literatura paraguaia foi a fuga de cérebros: autores e intelectuais não se estabeleciam no país devido às sucessivas ditaduras. Roa Bastos, apesar de contra a vontade, também esteve nessa situação, porém, a situação de exílio causou angústias que geraram a sua literatura. Krysinski (2005 p. 312) afirma que Augusto Roa Bastos se considerava um escritor forjado pela imposição do exílio. Como El trueno entre las hojas, Roa Bastos evidencia que não podemos jamais negociar a escolha do nosso lugar de nascimento, pois "trazemos conosco a fatalidade do lugar de onde viemos ao mundo. Nossa pátria nos cola na pele. Ela nos acompanha onde quer que estejamos. É isso que nos ensina esse livro".

A obra é composta por dezessete contos ambientados na primeira metade do século XX em que se observa uma crítica visceral e contundente à sociedade paraguaia. Os contos possuem como característica uma cadência rítmica introduzida na prosa. Do ponto de vista expressivo, Roa Bastos apela, neste livro, ao uso de um expressionismo potente, conseguindo, mediante profundas incisões, traços e oposições sobre uma realidade cujos matizes oscilam entre o branco da inocência e o vermelho da violência. (SAGUIER, 1976). Além disso, os contos permitem observar uma característica que permeia toda a obra de Roa Bastos: o bilinguismo. O Paraguai é o único país latino-americano oficialmente bilíngue e, durante a década de 1950, menos de seis por cento da população tinha o espanhol como língua materna. O autor constrói personagens que falam Guarani, que mesclam o idioma com a língua oficial castelhana e, dessa maneira, a importância da oralidade é sentida na constituição de suas narrativas.
Considerando o significado da obra de Roa Bastos para o Paraguai e para a literatura hispanoamericana, neste artigo analisaremos o conto $\mathrm{La}$ Rogativa, integrante da obra El trueno entre las hojas. Porém, iremos propor uma leitura do conto ancorada em aspectos psicológicos e sociais.

La Rogativa é um conto dividido em cinco blocos numerados. Principia com a descrição da personagem Poilú, uma menina, ainda na primeira infância, que vive com sua mãe em uma pequena povoação. O modo com que a personagem é apresentada é de certa forma chocante: "Una pequeña larva humana avanzando entre los amarillentos colgajos de las hojas" (ROA BASTOS, 1968, 153). Poilú é comparada a um animalzinho faminto, pois é retratada comendo terra, remexendo o solo do bananal. Tal comportamento ocorre devido ao fato de não chover há meses e consequentemente, a seca castiga fortemente o vilarejo. A fome é tão devastadora que a criança precisa comer terra para aplacá-la.

A segunda parte do conto apresenta a mãe de Poilú, Anuncia, e a realidade que o povoado enfrenta - a seca de mais de seis meses que estava causando angústia e desespero, que parecia renovar a fé da aldeia inteira. Todos os seus habitantes - até mesmo os criminosos mais execráveis - estavam na capela, rezando, implorando a Deus por chuva - La rogativa, a imploração. Anuncia cria a filha sozinha e vive da colheita de mandioca e milho. Com a seca, não há trabalho, então, todos os dias, a mulher fecha a cabana, deixa a filha sozinha e vai à capela e une sua voz na imploração por chuva. Poilú, assim como outras crianças, corre solta nos bananais, tentando aplacar o desespero da fome. Assim, a criança age como um animalzinho: "Las moscas la seguían y se enredaban de tanto en tanto em las greñas queriendo llegar hasta los granos. Poilú no hacía el más mínimo ademán de defenderse. El sol, las moscas, el hambre eran partes de su mundo; no los sentía enemigos suyos". (ROA BASTOS, 1968, p.156).

A menina vai à busca de água, mas todos os poços estão secos. Instintivamente, vai ao encontro de Felipe Tavy, um velho louco que morava em uma 
gruta, e que torna-se amigo de Poilú, a única pessoa que a trata como um ser humano, contando histórias e dialogando de igual para igual. Felipe conversa com Poilú e apresenta à menina um mundo de fantasia.

—Sí, Celipe. ¿Por qué no hay agua y no’ tamo mu riendo de sed?

-Porque en el cerro Kuruzú hay un tigre azul que se tragó toda el agua. Hata que el tigre orine no vamo' a tener ma' agua.

- ¿Y cuándo va a orinar el tigre?

-Cuando en el plan del arroyo florezca un Yasymoroti

-Pero allí hay piedra mucho ité por toda parte. ¿Cómo pikó va a salir el flor, Celipe?

Felipe ahuecaba la voz y guiñaba un ojo mirando para todas partes:

- Hay un abujero en la piedra del plan, frente mimo a mi cueva. Por allí va a crecer el flor del agua.

- ¿Y por qué no te va' a la capilla a rezar con lo' jotro kuera?

-Na.. Yo no soy loco como lo'jotro... No e' allí que hay que apretar la verija al tigre... Dios no etá en la capilla... Allí solamente hay el mal aliento de la' vieja bruja... (ROA BASTOS, 1968, p.157).

No trecho acima, observamos que, na fala de Poilú e Felipe, termos guaranis se integram ao espanhol, ressaltando o bilinguismo que constitui a população paraguaia. Felipe diz para a menina que apenas choverá quando certa flor nascer nas margens do Arroio, pois a flor fará com que o tigre urine e, assim, choverá. Chama a atenção que Felipe é o único adulto do vilarejo que não se encontra na capela, rezando por chuva.

Um dia, pergunta a sua mãe o porquê de ir todo dia rezar na capela, sua mãe responde que é para implorar a Deus por chuva e Poilú questiona esta "verdade". "Celipe dice que no e' allí donde hay que apretarle la verija al tigre". (ROA BASTOS, 1968, p. 157). Anuncia se escandaliza com a resposta e reage de forma violenta, proibindo sua filha de falar com o velho do arroio. Poilú argumenta que Felipe é o único que lhe conta histórias, mas a mãe não cede. $A$ mãe afirma que as histórias de Felipe entraram na cabeça da menina como se fossem vermes e perturbaram seu juízo. Então, a ameaça e para que suas palavras tenham um peso maior, diz que o próprio Deus amassará a cabeça da menina como se fosse uma melancia se ela voltasse a falar com o velho Felipe. Mas a menina, agora um ser pensante, mesmo calada, sem enfrentar sua mãe, questiona-se, se interroga e não aceita as palavras maternas como verdades absolutas. Porém, para evitar o confronto, promete não falar mais com Felipe Tavy.

A quarta parte do conto inicia com os questionamentos internos de Poilú, que, após a confrontação materna, é dominada pela sede que arranha sua garganta e a faz ir, inconscientemente, ao poço, porém, não há água. Mesmo assim, a menina olha para o poço como se estivesse hipnotizada: sabe que não há água, mas é movida pela esperança do dia que Felipe anuncie 0 nascimento de uma flor no arroio. Na quinta e última parte do conto, Felipe encontra Poilú debruçada sobre o poço e a interroga. A menina avisa que não pode mais falar com ele. Felipe diz que concorda com a mãe de Poilú, pois realmente poderá criar vermes na cabecinha da menina. Porém, afirma que é uma lástima não poder falar com Poilú justamente agora que a flor de Yasymoroti havia começado a florescer. Ao ouvir isso, o rosto da criança se ilumina e "era la belleza de una nube reflejada en un charco oscuro. En alguna parte del universo Poilú en ese mbmento era hermosa como una flor cuya abso luta perfección residía en que era todavía increada". (ROA BASTOS, p. 160). Essa metáfora - Poilú é uma flor cuja perfeição advém do fato de ainda não ter sido criada - de certa maneira, sintetiza o conto e já adianta ao leitor que a menina terá sua trajetória interrompida. A ideia de que uma flor estava nascendo no fundo das margens do arroio e que aquilo representava uma esperança, encantou Poilú. A menina então afirma que como logo irá chover, ela poderá sempre conversar com Felipe, pois o mau humor de sua mãe terá passado. O ancião se despede da menina, mas, de certa forma, espantado com a sabedoria da criança. Porém quando olha para trás percebe que a menina se aproxima perigosamente das pedras talvez tentando ver a flor nascer -. Felipe grita pelo nome da menina, mas ela não o ouve - e nunca mais ouvirá. 
O desfecho do conto é trágico: após buscas pelo paradeiro da menina, Anuncia responsabiliza Felipe pela morte de sua filha e incita os habitantes do povoado contra ele. Guiados por uma violência virulenta, a multidão apedreja o ancião até a morte e não se dá conta que, no mesmo instante, uma chuva principia. O conto encerra com a informação de que para agradecer a chuva, haverá em breve uma missa em ação de graças na capela de Santa Clara.

\section{La Rogativa e as relações entre oralidade, subjetividade e leitura}

La Rogativa é a história de um mundo em crise, de um espaço abandonado pela esperança. A história de um povo sofrido que reage de forma violenta às adversidades, talvez por estar perdendo sua identidade e capacidade de ser sensível ao outro. A seca que devasta o povoado não é somente devido à falta de água, há uma escassez de esperança. Michele Pètit (2009) aponta que as desigualdades sociais vulnerabilizam homens, mulheres e crianças. Porém, os recursos materiais, culturais e afetivos das pessoas podem construir uma espécie de armadura que os faz resistir às adversidades. A antropóloga francesa afirma que os

mitos, contos, lendas provérbios, cantos, refrãos permitiam-Ihes em certa medida, simbolizar emoções intensas ou acontecimentos inesperados, representar conflitos, dar forma a paisagens interiores, inserindo-se ao mesmo tempo em uma continuidade, uma transmissão. Construir um sentido. Ao menos, esse era o caso das sociedades que mantiveram uma mitologia viva, reformulada e enriquecida ao sabor dos encontros. Entretanto, hoje em dia, em muitos lugares, a tradição oral se encontra desarticulada, as balizas simbólicas desorganizadas, com todos os riscos que comporta uma tal alteração da "rede" da cultura. (PÈTIT, 2009, p. 25-26)

A literatura oral, a manifestação cultural, são, assim, armaduras que auxiliam comunidades e sociedades no enfrentamento de problemas. Porém, há sociedades em que a oralidade enquanto manifestação cultural foi esquecida e, dessa forma,as pessoas perderam um espaço importante de construção de subjetividades. Esta parece ser a realidade do povoado de Poilú, em que os habitantes parecem desprezar as lendas, tradições indígenas e ritos antigos, que auxiliam na superação de vivências dolorosas, contribuem para elaborar perdas, assim como reestabelecer laços sociais. Sem o exercício da oralidade, os adultos do povoado parecem não conseguir enfrentar a realidade da seca e a única alternativa que encontraram é ir à igreja e implorar por chuva, rogando por milagres. Mas não há espaço para o diálogo, para a construção de uma genuína esperança.

Se num espaço marcado pela desesperança os adultos se sentem perdidos para lidar com conflitos, o que dizer das crianças? Poilú, no início do conto, retrata de forma brutal a infância desprovida de acesso à cultura. A menina está animalizada, não apenas pela fome, mas pela falta de identidade, ela não se reconhece como parte de uma comunidade e precisa apenas satisfazer suas necessidades básicas, a saber: a fome e a sede.

De certa maneira, é Felipe que apresenta à Poilú a leitura e a capacidade simbólica. Não a leitura dos livros, a leitura acadêmica do mundo letrado, mas a leitura do mundo, da oralidade, da fantasia. A justificativa que o velho dá para a seca no povoado, ancorada no folclore e na fantasia, desencadeia em Poilú a possibilidade de sonhar. Michèle Petit (2008) afirma que a leitura tem o poder de despertar em nós regiões que estavam até então adormecidas. É o que ocorre com Poilú. Isso porque a menina vive um mundo seco, em que sua mãe a trata de forma imperativa e em que o sonho e a ilusão não têm espaço, nem mesmo ser criança lhe é permitido. Poilú não tem o direito de fantasiar e criar mundos de infinitas possibilidades e seres, tão marcantes da fase em que a menina se encontra. A fantasia tem, na infância, uma função importante, pois as crianças aprendem a constituir sua subjetividade por meio dela. Sem imaginação a criança não tem meios de constituir sua identidade.

Felipe age como um mediador cultural em relação à Poilú. Segundo Pètit (2009, p. 50), "ao olhar a criança ou adolescente de uma outra forma, os 
mediadores culturais criam uma abertura psíquica". Felipe apresenta a menina lendas, contos orais, faz uma mediação da criança com sua cultura, ao mesmo tempo, em que a ouve e Ihe dedica uma atenção singular. Atenção que Poilú não recebe de sua mãe.

Petit (2008) afirma que a maioria dos jovens tem grande dificuldade de encontrar um lugar neste mundo, não só por razões econômicas, mas também afetivas, sociais, sexuais e existenciais e Poilú parece estar neste dilema. Não sabe quem é, foi acostumada a apenas sobreviver e, pela primeira vez, pensa, vivencia e se percebe como ser humano apto a recorrer à sua capacidade e força interna, despertada pelas histórias que a possibilitaram dar início a um processo de resiliência, tão importante em momentos de dor e trauma. A fantasia contribui para que a criança reconheça e entre em contato com seus sentimentos, entre eles a agressividade. Por meio da fantasia, a criança aprende a controlar este sentimento, buscando, também, uma forma socialmente aceita para descarregar sua energia agressiva.

O pediatra e psicanalista inglês Donald Woods Winnicott traz a llusão e a Criatividade como argumento central em sua teoria do desenvolvimento. A distinção entre realidade interna e realidade externa é uma tarefa da vida inteira a que se dedicam os seres humanos, visto que estamos irremediavelmente condenados à tensão inerente à tentativa de discriminação dentro/fora, situação que é inaugurada na relação mãe-bebê e continua pelo resto da vida.

A mãe suficientemente boa, segundo Winnicott (1965), permite que surja uma superposição entre o seio que o bebê acredita estar criando e aquele que Ihe é de fato oferecido. Esta se caracteriza como a primeira ilusão da vida de um ser humano. Ou seja, o seio que the é apresentado e o cuidado que lhe é dispensado, foram por ele concebidos e estão sob seu controle onipotente. Esta experiência de onipotência é possibilitada ao bebê pela mãe suficientemente boa, ao iludi-lo de que ele tem a capacidade de criar a realidade externa de acordo com seus desejos internos, permitindo que o bebê expresse sua criatividade primária e sinta-se criando o objeto subjetivo e seu significado. Isso serve de suporte e função ao repouso criativo, tão importante e necessário na vida adulta.

Tendo em vista que, para a teoria winnicottiana, a vida pulsional e psíquica só tem satisfação frente à presença de uma mãe que dê suporte ao bebê para que ele organize suas experiências e perceba significado nelas, é possível relacionar esta importante função ao que Felipe Tavy faz com Poilú, Ihe permitindo ter acesso ao seu potencial criativo e de ilusão, não diferente do que os adultos da aldeia fazem, como se percebe em: "Mas a angústia e o desespero fizeram desabrochar vigorosamente a fé da povoação. A capela tornou-se pequena para conter este repentino florescimento do espirito religioso." (ROA BASTOS, p. 155).

A área da llusão é um espaço potencial de repouso e experimentação em que o sujeito está momentaneamente desobrigado de traçar uma linha delimitadora entre o dentro e o fora. Este é o lugar em que, para o teórico inglês (1964), experimentamos a vida, justamente por abrigar a criatividade.

Ao desencorajar Poilú de acreditar que a seca é um pássaro grande e que um tigre azul engoliu toda a água do povoado, dependendo da urina deste para o retorno da chuva, Anuncia, sua mãe, a impede de entrar em contato com seu potencial criativo, o qual serviria para acalmar sua angústia sem nome, visto que, a criança não sabia o que estava acontecendo no povoado.

A área da llusão, ao ser preservada, proporciona ao sujeito a alternativa de se por em continuidade com o mundo e cria-lo, assim como cria a si próprio. Esta criação, segundo Jurandir Costa (2004, p.117),significa a captação seletiva dos aspectos das coisas do mundo úteis para a ação; e, ao agir no mundo, o sujeito confere significância ao desejo e realidade do eu interior.

Michele Pètit vai de encontro aos estudos de Winnicott quando pontua que o estudioso

comentou também sobre o papel exercido pelo rosto da mãe, em direção ao qual a criança conduz o seu olhar esperando que ele reflita alguma coisa sobre ela mesma, esse rosto que tenta "ler" para decifrar o humor da 
pessoa que cuida dela, "assim como estudamos o céu para adivinhar o tempo que vai fazer". A psicoterapia era "um derivado complexo do rosto que reflete o que ali está para ser visto". A leitura também, talvez, pois o que a criança explora ou teme nos livros é em larga escala esse ser estranho, inquietante, fascinante, que está dentro dela, do qual ela ignora porções inteiras e que às vezes se revela, se constrói por acaso quando encontra uma página, esse lugar distante no interior, o mais íntimo, o mais escondido, que é , contudo, onde nos abrimos para o outro. Aí encontra-se grande parte do segredo que procuram os leitores, às vezes freneticamente - e que outros, ao contrário esforçam-se para evitar. (PĖTIT, 2009, p.53, grifo da autora)

No trecho acima, Pètit tece uma comparação entre as descobertas afetivas que o bebê faz em relação a sua mãe e a descoberta que a leitura desencadeia subjetivamente nas crianças. Em ambas as relações há a mesma dinâmica, é preciso observar o externo, para constituir o interno. Ao entender e decifrar os movimentos de sua mãe, a criança entende que comportamentos deve ter. Ao ler e tomar contato com textos diversos, a criança descobre melhor partes de si mesma. Assim, a leitura contribui para que crianças e adolescentes se encaminhem mais no sentido do pensamento do que da violência e "em certas condições, a leitura abre possibilidades onde parecia não existir margem de manobra" (PÉTIT, 2008, p. 13). A autora ressalta, ainda, que é sempre na intersubjetividade que os seres humanos se constituem e suas trajetórias podem mudar de rumo depois de um encontro. É o que de certa forma acontece com Poilú, encontrar Felipe faz com que a menina tenha acesso à leitura, à vivência literária mesmo em sua forma oral. Petit ressalta que ler permite ao leitor, às vezes, decifrar sua própria experiência. É o texto que lê o leitor, de certo modo é ele que o revela; é o texto que sabe muito sobre o leitor, de regiões dele que ele mesmo não saberia nomear. As palavras do texto constituem o leitor, Ihe dão um lugar. Poilú, faminta e animalizada, encontra a si mesma após ser despertada pelas lendas e histórias de Felipe. "Poilú no sabía qué pensar. Felipe y su madre con tendían en la nebulosa nuez que la hidrocefalia todavia no había acabado de inundar." (ROA BASTOS, 1968, p. 157). A menina pensa, reflete, tem uma luta interna.
Michèle Petit (2008) ressalta que a linguagem não pode ser reduzida a um instrumento, pois ela tem a ver com a construção de nós mesmos enquanto sujeitos falantes. A autora francesa defende que a vida dos seres humanos é determinada em grande medida ao peso das palavras ou ao peso da sua ausência. Podemos relacionar isso a Poilú, a menina animalizada pela fome e pela ausência da imaginação perde sua identidade enquanto ser humano. Petit afirma que quanto mais formos capazes de nomear o que vivemos, mais aptos estaremos para vivê-lo e transformá-lo. Enquanto o oposto, a dificuldade de simbolizar, pode vir acompanhado de uma agressividade descontrolada. A leitura contribui, assim, para criar um jogo no tabuleiro social, para que "os jovens se tornem um pouco mais atores de suas vidas, um pouco mais donos de seus destinos e não somente objetos do discurso de outros". (PETIT, 2008, p.100)

Entretanto, Poilú não teve tal oportunidade. O desfecho da personagem, impreciso, indefinido, mas indelevelmente trágico, é coerente com o tom de denúncia assumido pelo conjunto da obra de Roa Bastos. A menina sonhadora, pensante e criativa não tem espaço para florescer em uma sociedade agressiva, árida e violenta.

\section{Considerações finais}

No presente artigo, tivemos o objetivo de refletir sobre infância, literatura e oralidade a partir da leitura do conto La rogativa e, para tanto, propomos um diálogo entre a psicanálise winiccottiana com os estudos de Michèle Petit. $O$ objetivo foi alcançado, uma vez que, apontamos na narrativa, passagens e simbolismos que nos fazem refletir sobre a condição da infância. Além disso, revitalizar e apontar a atualidade da obra de Roa Bastos é fundamental, tanto para a fortuna crítica do autor paraguaio como para problematizar questões suscitadas em suas narrativas.

Obviamente, que a leitura de La rogativa proposta nesse trabalho, não é a única, tampouco, seria nossa intenção esgotar as possibilidades de 
análise e discussão desse conto. Roa Bastos criou uma narrativa permeada de camadas de sentidos e muitas questões poderiam ser discutidas. Este artigo não teve o objetivo de analisar profundamente a crítica à religião, à hipocrisia social e a desigualdade marcante do Paraguai na metade do Século XX. Mas é conveniente pontuar o quão são importantes os fatores citados para a compreensão global do conto. O conto retrata situações trágicas em todos os níveis: familiar, social e cultural. Familiar, pois retrata uma família desestruturada em que a mãe não envolve sua filha com a afetividade necessária a uma criança em desenvolvimento. Social, pois a fome, a desigualdade e a pobreza material e cultural fazem com que a população seja vulnerável e que em situações extremas responde com violência e brutalidade. E, finalmente, uma tragédia cultural, pois o conto retrata a marginalização do patrimônio oral de um povo: um povoado que despreza a cultura oral e perde assim sua identidade.

Nossa análise teve como foco principal fazer perceber o contundente alerta presente no conto de Roa Bastos em relação ao dano irreversível que a falta de fantasia, de leitura e de imaginação pode causar aos indivíduos. Chamar atenção para essa questão torna-se vital, principalmente, nos tempos em que vivemos, em que muitas vezes a importância de ler, fabular e brincar é menosprezada por diversos segmentos da sociedade. Cumpre mencionar que o conto de Roa Bastos pode ser lido como um manifesto em defesa dos mitos e lendas paraguaios, defesa da oralidade enquanto manifestação cultural.

\section{Referências}

COSTA, Jurandir Freire. Criatividade, transgressão e ética. In: PLASTINO, C. A. (Org.). Transgressões. Rio de Janeiro: Contra Capa, 2002. p. 63-76

KRYSINSKI, Wladimir. Augusto Roa Bastos: retrato em perspectivas. Revista USP, São Paulo. set./nov. 2005.

PETIT, Michèle. A arte de ler ou como resistir à adversidade. Editora 34, 2009.

Os Jovens e a leitura. Editora 34, 2008.
ROA BASTOS, Augusto. El trueno entre las hojas. Buenos Aires: Ed. Losada, 1968.

SAGUIER, Ruben. Augusto Roa Bastos e a Narrativa Paraguaia Atual. Curitiba: Letras, 1976.

WINNICOTT, Donald Woods. O ambiente e os processos de maturação: estudos sobre a teoria do desenvolvimento emocional. Porto Alegre: Editora artes médicas: 1990.

A criança e seu mundo. Rio de Janeiro:

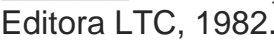

